\title{
Research on the Influencing Factors of Sales in Online Accommodation Market under Sharing Economy
}

\author{
Cai Dandan \\ Wuhan University of Technology \\ School of Management \\ Wuhan China \\ Cathy_cai_2014@163.com
}

\author{
Wang bin \\ Wuhan University of Technology \\ School of Management \\ Wuhan China \\ whutwb@139.com
}

\begin{abstract}
With the continuous improvement of information technology, the sharing economy has emerged, and has achieved tremendous development results. This study took xiaozhu.com as an example and studied from the following three perspectives: host attributes, customer attributes, and interaction attributes between landlords and customers. The study kept the price within a certain range and analyzed the impact of the above attributes on the sales volume of the listing with the regression analysis method to analyze the data crawled online. The results of the study indicate that the sales of a listing are not only positively correlated with the length of the cus tomer's comments, but also have a positive correlation with the interaction attributes of the landlord and the customer.
\end{abstract}

Keywords-sharing economy; trust; peer-to-peer platforms; short-term rental

\section{INTRODUCTION}

Under the influence of the Internet wave, the continuous development of information technology has greatly changed people's lifestyle and payment methods. The sharing economy is based on the Internet, providing platform services for resource providers who have idle resources and the corresponding resource demanders, and obtain corresponding money in return. According to data released by the Ministry of Information and Industry Development of the People's Republic of China in February 2018, the annual report of the China's Shared Economy Development (2018) shows that the market of sharing economy in China reached 4.92 trillion yuan in 2017, growing at a rate of $47.2 \%$. Shared accommodation, as an important part of the sharing economy, has changed people's accommodation for travel. Compared with the traditional hotel accommodation mode, shared accommodation not only utilizes the socially idle accommodation resources, but also meets the diverse needs of customers. Therefore, it has been favored by a large number of young people.

This article will use pig short-term rental as an example to explore the impact of various factors on product sales under the shared economy model from the perspective of landlords, customers, and the interactive nature of both. Taking into account the significant differences in product sales under different price conditions, therefore, in the analysis of this paper, only considers the impact of online reviews on the sales of accommodation in the same price range.

\section{RELATED Literature}

\section{A. Aspects of the online reviews}

At present, research on online reviews mainly includes the following three points: the dimensions of online reviews, the impact of online reviews on consumers' purchase intentions, and the emotional polarity analysis of online reviews. Fang (2016) shows that experience-based products and search-based products can significantly affect the regulatory role of the brand through empirical analysis ${ }^{[1]}$. Mudambi S M (2010) argues that review length, commentary extremes, and product type can significantly affect the usefulness of online reviews ${ }^{[2]}$. Zhang et al (2016) argue that text length and seller response has a significant positive effect on the usefulness of online reviews through a large number of sample analysis, among which, seller responses can significantly affect the effectiveness of the comments in products ${ }^{[3]}$. Nelson (1970) argues the influence of online reviews will also be influenced by the type of product. He divides the product into experience products and search products according to the ability of consumers to obtain product quality information before purchase. And that consumers search for goods will conduct a large number of search behavior, the search behavior of the experience of goods is relatively small ${ }^{[4]}$. In the study of consumer purchase intentions, Park et al (2009) find that for low-level professional consumers, the number of reviews has a greater influence on purchase intention ${ }^{[5]}$. Wa (2014) divides the dimensions of online commentary into three aspects: reviewer factor, comment content factor, and comment receiver factor. Using the perceived value of the product or service as an intermediary variable, she explores the relationship between online reviews, perceived value and purchase intention. Du et al. (2016) use the professional competence of the recipient as a moderator variable to construct a model for online reviews of consumer purchase intentions ${ }^{[6]}$. 


\section{B. Aspects of the sharing economy}

In the study of the sharing economy, Zhao et al (2017) use correlation analysis and regression analysis to analyze the data collected from the Airbnb website. The differences in the behavior of Chinese and American consumers on peer-to-peer platforms are compared and analyzed from the perspective of the quantity, price, and ratings of online reviews ${ }^{[8]}$. Ma (2017) takes the Xisozhu.com as an example and uses Stata and R software to analyze the impact of listings and landlord attributes on consumer purchasing behavior based on trust theory ${ }^{[9]}$. Xie and Shi (2016) consider the personal characteristics of the sharing subject and establish the basic framework of the trust formation mechanism under the sharing economy based on traditional trust theory research. They used the example of short-lease pigs in the housing sharing field as an example, and studied the impact of personal characteristics of shared entities on the mechanism of trust formation through correlation analysis based on SPSS software and path analysis based on LISRET software ${ }^{[10]}$.

\section{MODEL AND HYPOTHESIS}

\section{A. Trust Theory}

The sociologist Lewis \& Weigert (1985) systematically analyze the characteristics, dimensions, and basic types of trust, define trust as a quality within a group that is only relevant to the interactions between people and not to the personal qualities ${ }^{[11]}$, which has been affirmed by many scholars of ecommerce transaction trust theory. Trust is the willingness of the trusting subject based on certain expectations, and is influenced by the goodwill, ability, and honesty of the trusting object. Therefore, in the trust theory, the seller's goodwill, ability and honesty are considered as one of the important factors in constructing trust.

\section{B. Online interaction}

The definition of interactivity can be explained in the following three aspects. From the perspective of functionality, an interactive website should satisfy good match and respond quickly to user input. From the perspective of perception, interaction is defined as the perception of individual users in the interactive process, the perception of the two parties' communication methods and the psychological feelings of the degree of control; From the point of view of process, interaction is a process of information exchange, a process of mutual interaction between two parties. In the case of shared accommodation, online interaction is the communication and exchange between sellers and buyers. From the point of view of social interaction theory and social exchange theory, online interaction can send a signal to consumers. Such signals can be caused by consumer's psychological processing and judgment, which can lead consumers to believe in online merchants ${ }^{[12]}$. Therefore, online interaction can influence consumer trust, which is one of the important factors that this article combines online interaction attributes and trust models.

\section{Hypothesis}

Based on the trust theory and online interactive properties, this paper studies the impact of landlords, customers, and the interactive attributes of the two on the sale of properties. Consumers will only make purchasing decisions based on the trust of trusted entities. In the property of the landlord, we select the three variables of confirmation time, the acceptance rate, and whether to open the homepage, which represent benevolence, ability, and integrity in the trust model. In customer attributes, we select three variables: review length, review number, and photo number. In the interaction properties, select the response rate and review length rate as the exchange between the buyer and the seller. Model diagram as shown:

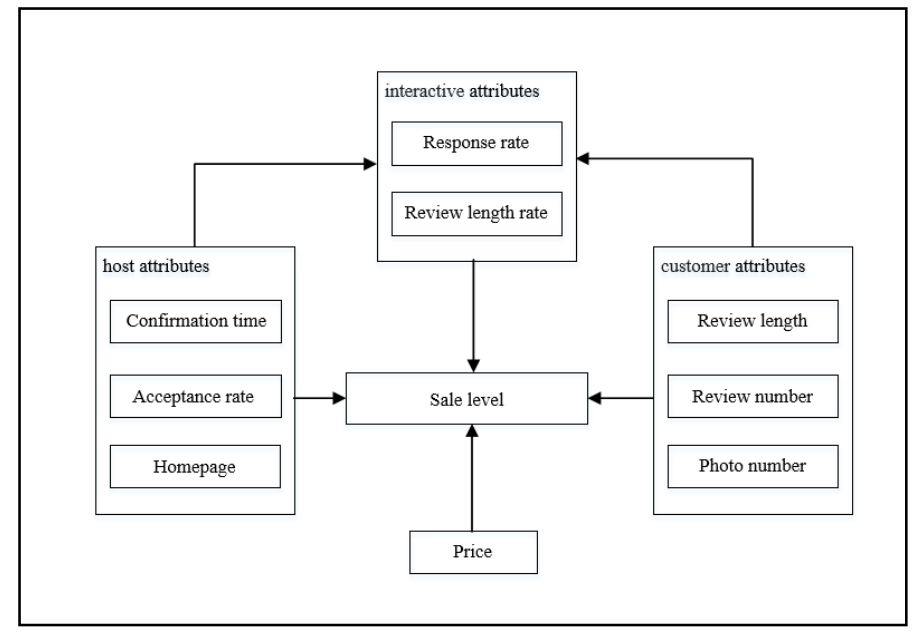

Fig. 1. Model diagram

The definition of the nine variables in the model is as follows:

TABLE I. THE DEFINITION OF VARIABLE

\begin{tabular}{|c|c|c|}
\hline Dimensions & Variable & Definition of variable \\
\hline \multirow{3}{*}{$\begin{array}{c}\text { Host } \\
\text { attributes }\end{array}$} & Confirmation time & $\begin{array}{l}\text { The average time from buyer orders } \\
\text { to seller orders }\end{array}$ \\
\hline & Acceptance rate & Seller orders/orders from buyers \\
\hline & homepage & Open to 1 , not open to 0 \\
\hline $\begin{array}{c}\text { Room } \\
\text { attributes }\end{array}$ & price & The price of the room \\
\hline \multirow{3}{*}{$\begin{array}{l}\text { customer } \\
\text { attributes }\end{array}$} & review length & $\begin{array}{l}\text { The average number of words per } \\
\text { comment }\end{array}$ \\
\hline & review number & The number of online reviews \\
\hline & photo number & $\begin{array}{l}\text { Number of reviews for picture } \\
\text { comments }\end{array}$ \\
\hline \multirow{2}{*}{$\begin{array}{l}\text { interactive } \\
\text { attributes }\end{array}$} & response rate & $\begin{array}{l}\text { The number of comments the seller } \\
\text { replied/ the number of comments by } \\
\text { the buyer }\end{array}$ \\
\hline & review length rate & $\begin{array}{l}\text { Seller Comments Average Words/ } \\
\text { Buyers Average Number of Words }\end{array}$ \\
\hline
\end{tabular}

\section{Impact of Landlord Attributes on Sales Volume}

In the influence of research trust theory on the sales volume of listings, Ma proves that the landlord's average confirmation time, order acceptance rate, and opening homepage represent the goodwill, ability, and honesty in the trust theory, respectively, and have a positive influence on the sales of listings through empirical research; Ahn et al. point out that service quality is an important dimension for 
enhancing trust and promoting purchases. The quality of service here refers to the effectiveness and timeliness of multiparty communication mechanisms, such as timely handling of consumer dissatisfaction, giving consumers help, providing additional services, and solving their problems ${ }^{[13]}$; Lu et al. point out that the seller's ability to generate trust has a significant positive effect on the consumer's buying propensity [14]; Connolly and Bannister's research finds that consumers' trust in online shopping is influenced by the honesty and integrity perceived by sellers ${ }^{[15]}$. Based on the above literature, we propose the following hypothesis:

H1: The time of reservation confirmation will have a positive effect on the sales of the property

H2: The landlord's acceptance rate will have a positive effect on the sales of the property

H3: Landlord opens home page Positively Affects Sales of Listings

\section{E. The effect of customer attributes on Sales Volume}

Guo et al. (2015) confirm in the study that the diagnostic text of the review text will have an impact on consumer decision making and will have a positive effect on electronic products. Review length include the number of texts and the quality of the text ${ }^{[6]}$. Based on the above literature, we propose the following hypothesis:

H4: Review length have a positive effect on home sales

H5: Review number has a positive effect on the sales of listings houses

H6: Photo number has a positive effect on the sales of

\section{F. Impact of Interactive Attributes on Sales Volume}

Zhao (2015) studies the influence of online interaction on consumer trust in B2C online shopping based on the perspective of liveliness. The research results show that the interaction between consumers and online sellers increases the sense of social presence of consumers, and the social presence they generate can increase consumers' trust in the integrity and goodwill of B2C online stores ${ }^{[17]}$. Based on social sensation and social exchange theory, Mchnight et al. believe that the trust between buyers and sellers is established in the process of mutual interaction. The positive interaction shows the seller's goodwill attitude, which helps to break into the buyer's trust in the seller. Based on the above literature, we propose the following hypothesis:

H7: Response rate has a positive effect on sales

H8: Review length rate positively Affects Listing Sales

\section{EMPIRICAL RESEARCH}

\section{A. Data Collection and Selection}

At present, with the continuous development of the sharing economy, people's acceptance of sharing forms is also increasing. However, for the moment, the important application scenario for online short-term rentals is travel. Therefore, this article selected two major tourist cities in China, Chengdu and Xiamen, as representatives, to study the impact of online shortterm rental market listing sales. In accordance with the recommended order of short-lease for xiaozhu.com, each city climbed the top 250 store information. For the landlord attribute, the main information captured includes the length of confirmation, the rate of orders, and whether or not to open the home page. For customer attributes, the main captured information includes the customer's online reviews. The interactive attributes between the landlord and the customer, the main information captured includes the landlord's online response rate and online reply comments. At the same time, we also considered the impact of price factors on the sales of listings in the model. According to the survey report of iResearch, the average daily price of selected rooms by users through the online short-term rental platform is between 200500 yuan, accounting for $80.5 \%$ of the online short-term rental market. Therefore, we only select houses with prices in the 200-500 range. In addition, consider the diversification of online short-term rental forms such as full rental, bed rental, and sofa rental, but there are fewer landlords for bed rental and sofa rental, accounting for only $3 \%$ of the entire housing market. So we only crawl the whole set of rented housing as a research object.

After the above data collection and screening, a total of 460 landlord information and 10,772 online commentary information are selected.

\section{B. Variable Description}

This study is based on the sales of the property as the dependent variable, the price attribute of the property as the control variable, the landlord property and the customer property, and the interaction between the two as independent variables. In order to better perform quantitative analysis, data coding is performed on whether to open a personal homepage variable, open personal homepage $=1$, not open personal homepage $=0$. Descriptive statistics for variables are shown in the following:

TABLE II. THE DESCRIPTIVE ST ATISTICS OF VARIABLES

\begin{tabular}{|c|c|c|c|c|c|}
\hline & Variable & Mean & Std. Dev. & Min & Max \\
\hline $\begin{array}{c}\text { Dependent } \\
\text { variable }\end{array}$ & Sale level & 135.18 & 210.81 & 1 & 1460 \\
\hline $\begin{array}{c}\text { Control } \\
\text { variable }\end{array}$ & price & 321.88 & 83.04 & 200 & 500 \\
\hline \multirow{4}{*}{$\begin{array}{c}\text { Independent } \\
\text { variable }\end{array}$} & $\begin{array}{c}\text { Confirmation } \\
\text { time }\end{array}$ & 5.41 & 23.98 & 0 & 53 \\
\cline { 2 - 6 } & Acceptance rate & 0.86 & 0.11 & 0.25 & 1 \\
\cline { 2 - 6 } & review number & 23.23 & 29.46 & 0 & 223 \\
\cline { 2 - 7 } & photo number & 5.58 & 8.23 & 0 & 63 \\
\cline { 2 - 7 } & review length & 19.25 & 14.31 & 0 & 115 \\
\cline { 2 - 7 } & response rate & 0.84 & 0.3 & 0 & 1 \\
\cline { 2 - 7 } & $\begin{array}{c}\text { review length } \\
\text { rate }\end{array}$ & 0.4 & 0.37 & 0 & 2.75 \\
\hline
\end{tabular}

\section{Data Analysis and Discussion}

In this model, consider the impact of landlord attributes, customer attributes, and interactive attributes between the two on Sales volume keeping the prices below the same range. Correlation analysis and regression analysis are performed on each variable with SPSS. The results of correlation analysis and regression analysis are shown in the following table: 
TABLE III. RELATED ANALYSIS

\begin{tabular}{|c|c|c|c|c|c|c|c|c|c|c|}
\hline & $\mathbf{1}$ & $\mathbf{2}$ & $\mathbf{3}$ & $\mathbf{4}$ & $\mathbf{5}$ & $\mathbf{6}$ & $\mathbf{7}$ & $\mathbf{8}$ & $\mathbf{9}$ & $\mathbf{1 0}$ \\
\hline $\mathbf{1}$ & 1 & & & & & & & & & \\
\hline $\mathbf{2}$ & $.685^{* *}$ & 1 & & & & & & & & \\
\hline $\mathbf{3}$ & $-.156^{* *}$ & $-.175^{* * *}$ & 1 & & & & & & & \\
\hline $\mathbf{4}$ & .001 & .018 & -.091 & 1 & & & & & & \\
\hline $\mathbf{5}$ & $.484^{* *}$ & $.443^{* *}$ & $-.127^{* *}$ & .017 & 1 & & & & & \\
\hline $\mathbf{6}$ & -.043 & -.050 & $.106^{*}$ & $-.320^{* *}$ & -.028 & 1 & & & & \\
\hline $\mathbf{7}$ & $.064^{* *}$ & $.168^{* *}$ & $-.044^{* *}$ & $.159^{* *}$ & $.088^{* *}$ & $-.121^{* *}$ & 1 & & & \\
\hline $\mathbf{8}$ & $.563^{* *}$ & $.871^{* *}$ & $-.130^{* *}$ & .032 & $.378^{* *}$ & -.044 & $.170^{* *}$ & 1 & & \\
\hline $\mathbf{9}$ & $.042^{* *}$ & $-.126^{* *}$ & $-.054^{* *}$ & -.025 & $.091^{* *}$ & -.065 & $.368^{* *}$ & $.058^{* * *}$ & 1 & \\
\hline $\mathbf{1 0}$ & $.284^{* *}$ & $.317^{* *}$ & $-.098^{* *}$ & -.017 & $.181^{* *}$ & -.057 & $.045^{* *}$ & $.255^{* * *}$ & $.042^{* *}$ & 1 \\
\hline
\end{tabular}

For convenience of description: (1) Listing sales (2) Review number (3) Price (4) Acceptance rate (5) homepage (6) Confirmation time (7) Response rate (8) Photo number (9) Review length (10) Review length rate

As shown in the figure, the correlation coefficient between the dependent variables and independent variables, review number, whether or not to open the homepage, response rate, photo number, review length, and review length rate is between 0.042 and 0.685 . However, it is surprising that the confirmation time and acceptance rate have not passed the test, which means that hypotheses $\mathrm{H} 1$ and $\mathrm{H} 2$ are not established. After further analysis of the data, we can see that in terms of the acceptance rate, with the exception of a lower percentage of orders, over $80 \%$ of stores' acceptance rate is above $80 \%$, more than $90 \%$ of stores' acceptance rate have more than $70 \%$ of their orders. This means that except for a small number of stores, the other stores maintain a high rate of orders for sellers, which leads to the main reason why hypothesis $\mathrm{H} 1$ can't pass the test. As for the confirmation time, the data presents the same characteristics, and the average confirmation time of less than $20 \%$ of stores exceeded 5 minutes, which means there was no significant difference in the average confirmation time of shops.

\section{Conclusions AND Suggestions}

Based on the trust theory, this paper uses empirical research methods to explore the impact of customer attributes, landlord attributes, and interactive attributes between the two on the sale of listings. The data shows that in terms of landlord properties, confirmation time and acceptance rate can't pass the test, however, the homepage has a positive effect on the sales which also indicates that show more personal information to customers, can increase the trust of customers and increase the sales of orders. In terms of customer attributes, three of the review length, review number, and photo number pass the test. This shows that the comments left by the customers in the past are more important than the information displayed by the sellers themselves. In other words, the past review information left by the customer can increase the trust of the new customer. This also indicates that the new customer is more willing to trust the past customer than the information displayed by the seller. In terms of interactive attributes, both the response rate and the review length rate pass the test, which shows that more interaction between the hosts with customers will increase the trust of new customers to some extent.

Based on the above research results, this article comprehensively puts forward the following suggestions:

As far as the landlord is concerned, to increase the sales volume, the following points can be taken: (1) Show more personal information; the landlord can increase the amount of information he presents to the customer by opening the homepage to show his more credibility, so as to reduce the trust gap with the customer. (2) Increase interaction with buyers and focus on the quality of reply content. The trust between people is based more on communication between the two, especially in the internet. Actively maintaining communication with customers can promptly discover problems on the service, and at the same time, it also increases the trust of new customers to the store.

According to the research above, the response rate, whether to open the homepage, and comment information all affect the sales level. Therefore, the recommendation algorithm of the platform can comprehensively consider these attributes and set different weights according to the size of the influence relationship, thereby inspiring the hosts to improve its own service quality, enhance the user experience, and achieve the win-win mode of the platform, the landlord, and the customer. On the other hand, improving the establishment of customer evaluation index system can be taken into consideration. The current establishment of Xiaozhu.com only contains basic information and commentary information records for the customer, and does not establish a complete customer evaluation system. Therefore, the platform can consider the evaluation index system as an opportunity to establish a membership system, encourage more customers to participate in the entire process, and lay a foundation for the platform to establish a better trust mechanism.

\section{REFERENCES}

[1] FANG Jiaming, WANG Yuy ing, ZHAO Zhirong. Moderating Effects of Different Product Brand Reputations on Influencing Factors of Online Comment Us efulness[J]. Soft Science, 2016, 30(3):108-112. (In Chinese) 
[2] Mudambi S M, Schuff D. What makes a helpful online review? a study of customer reviews on amazon.com[J]. Social Science Electronic Publishing, 2010, 34(1): 185-200.

[3] Zhang Yanhui, Li Zongwei. Research on Influencing Factors of Usefulness of Online Comments: Based on the Regulatory Effects of Product Types [J]. Management Review, 2016, 28(10):123-132. (In Chinese)

[4] Nelson P. Information and Consumer Behavior[J]. Journal of Political Economy, 1970, 78(2):311-329.

[5] Park D H, Kim S. The Effects of Consumer Knowledge on Message Processing of Electronic Word of Mouth via Online Consumer Reviews. [J]. Electronic Commerce Research \& Applications, 2009, 7(4):399-410.

[6] Wan Yu. Study on the Impact of Online Reviews on Consumers' Purchase Will_-Based on the Perspective of Information Communication[D]. Zhejiang University, 2014. (In Chinese)

[7] Du Xuemei, Ding Wei, Xie Zhihong, et al. The Impact of Online Reviews on Consumers' Purchase Intention [J]. Management Review, 2016, 28(3): 173-183. (In Chinese)

[8] Zhao Jianxin, Zhu Ge, Song Lingyu. Research on the Influencing Factors of Residential Lodging Decision for Online Short-term Rental Platform[J]. Journal of Beijing University of Posts and Telecommunications: Social Science Edition, 2017(5):52-57. (In Chinese)

[9] Ma Yi. Research on the Influencing Factors of Sales of Online Shortterm Rental Listing Based on Trust Theory [D]. Wuhan University, 2017. (In Chinese)
[10] Xie Xuemei, Shi Jiaojiao. An Empirical Study on the Formation Mechanism of Consumer Trust under the Sharing Economy[J]. Technology \& Economy, 2016, 35(10):122-127. (In Chinese)

[11] Lewis J D, Weigert A. Trust as a Social Reality [J]. Social Forces, 1985, 63(4): 967-985.

[12] Zhao Hongxia, Wang Xinhai, Zhou Baogang. Online Interaction, Presence and Consumer Trust in B2C Online Shopping [J]. Management Review, 2015, 27(2):43-54. (In Chinese)

[13] Ahn T, Ryu S, Han I. The impact of the online and offline features on the user acceptance of Internet shopping malls[J]. Electronic Commerce Research \& Applications, 2004, 3(4):405-420.

[14] Lu Y, Zhao L, Wang B. From virtual community members to C2C ecommerce buyers: Trust in virtual communities and its effect on consumers' purchase intention[M]. Elsevier Science Publishers B. V. 2010.

[15] Connolly R, Bannister F. Consumer Trust in Electronic Commerce: Social \& Technical Antecedents[J]. International Journal of Social Sciences, 2007(4):221.

[16] Yanxi Xi, Guo Bin, Zhou Shasha, et al. How Online Review Affects Consumers: An Integrated Framework Based on Social Impact [J]. Journal of Xidian University (Social Sciences), 2015(1):1-18. (In Chinese)

[17] Zhao Hongxia, Liu Yanfeng. The Impact of Relationship Marketing and Online Store Reputation on B2C E-Commerce Transaction Trust[J]. Soft Science, 2013, 27(8):80-84. (In Chinese) 